\title{
Linking Science with Management of Freshwater Resources - A Forthcoming Collection of Papers in the Freshwater Systems Domain
}

\author{
Karl E. Havens \\ South Florida Water Management District, West Palm Beach, FL 33406
}

E-mail: khavens@ifas.ufl.edu

Received January 2, 2002; Accepted January 2, 2002; Published January 12, 2002

KEY WORDS: water resources, environmental management, aquatic sciences, resource management, ecosystem restoration, reservoir water quality

DOMAINS: freshwater systems, ecosystems and communities, environmental management and policy

With a rapidly growing human population and demand for freshwater, the world's lakes, rivers, and wetland ecosystems are being impacted at an ever-increasing rate. At no time in the past has there been a greater need for sound management of these aquatic resources and their watersheds, and for integration of science with resource management. Yet at a time when there is a dire need for water management agencies and scientific institutions to invest in more research, especially in water-stressed areas, just the opposite may be occurring. Budget cuts, changes in government policy, and other factors risk reduction, rather than strengthening, of the role of hypothesis-driven research in ecosystem management.

A special session at the 2002 meeting of the American Society of Limnology and Oceanography (ASLO, June 9-14, Victoria, B.C.) will address this important issue. The session, titled "Linking Science with Management of Freshwater Resources," supports the over-arching theme of the ASLO meeting inter-disciplinary linkages in the aquatic sciences and beyond. The session will include a keynote address by a leading expert in science-management linkages at the global scale, followed by several focused study papers that address specific cases where hypothesis-driven research is facilitating the effective management of freshwater systems. Topics will include development of reservoir water quality management plans based on empirical models for taste and odor, use of state/national partnerships in ecosystem restoration science, and use of ecosystem models for establishing hydrologic restoration goals in large lakes. Additional details regarding the 2002 ASLO meeting can be found at the conference web site: www.aslo.org/victoria2002

Research papers from this session will be peer-review and published in the Freshwater Systems domain of TheScientificWorld.

Karl E. Havens Principal Editor, Freshwater Systems January 2002 METHODS 
This article should be referenced as follows:

Havens, K. (2002) Linking science with management of freshwater resources - a forthcoming collection of papers in the Freshwater Systems domain. TheScientificWorldJOURNAL 2, 105-106. 


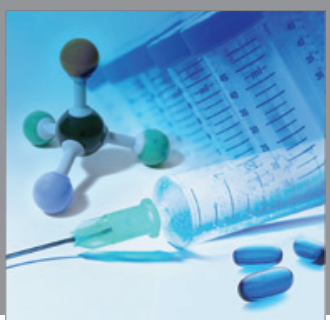

International Journal of

Medicinal Chemistry

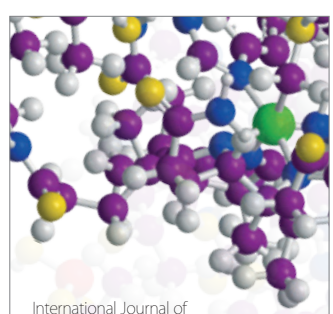

Carbohydrate Chemistry

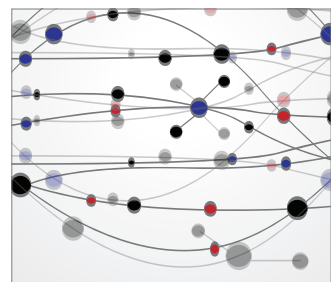

The Scientific World Journal
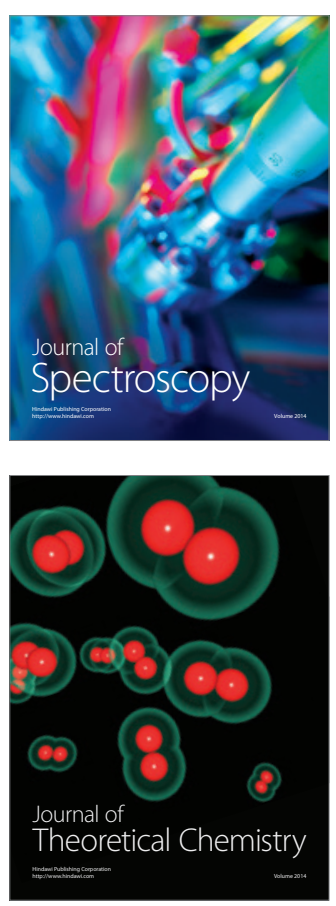
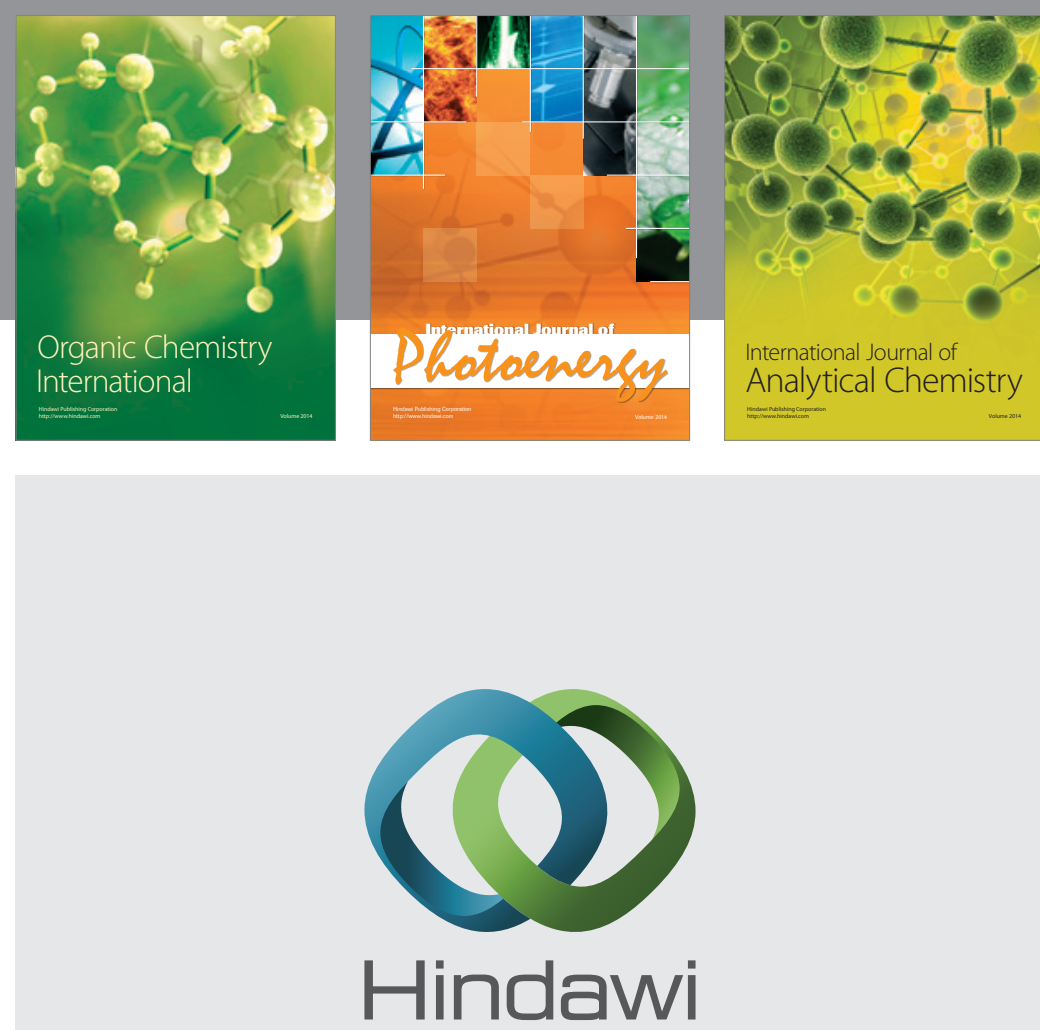

Submit your manuscripts at

http://www.hindawi.com
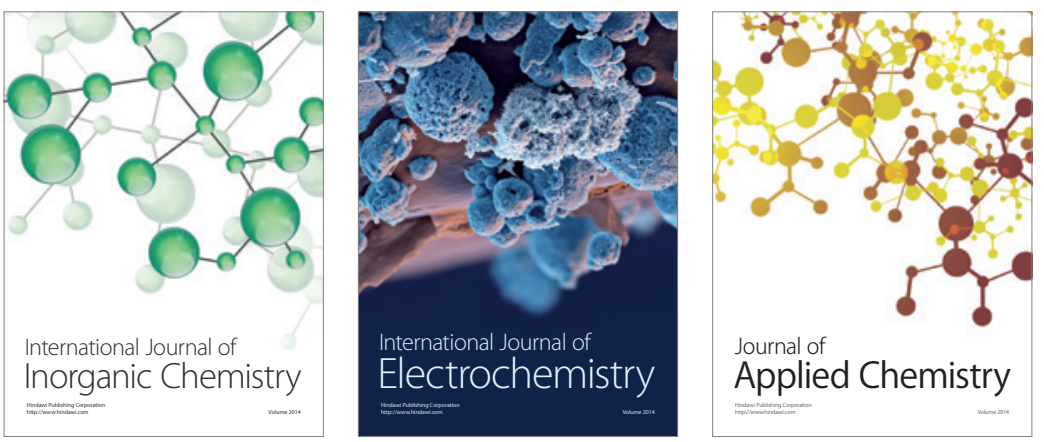

Journal of

Applied Chemistry
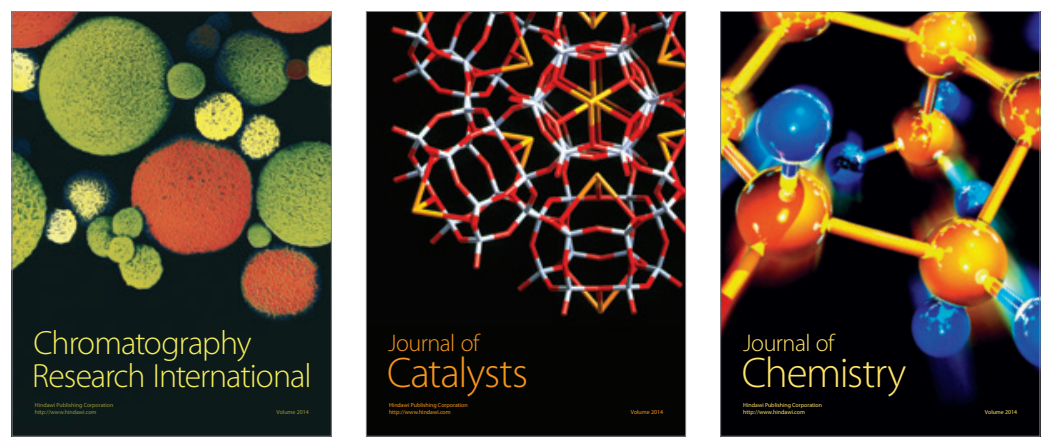
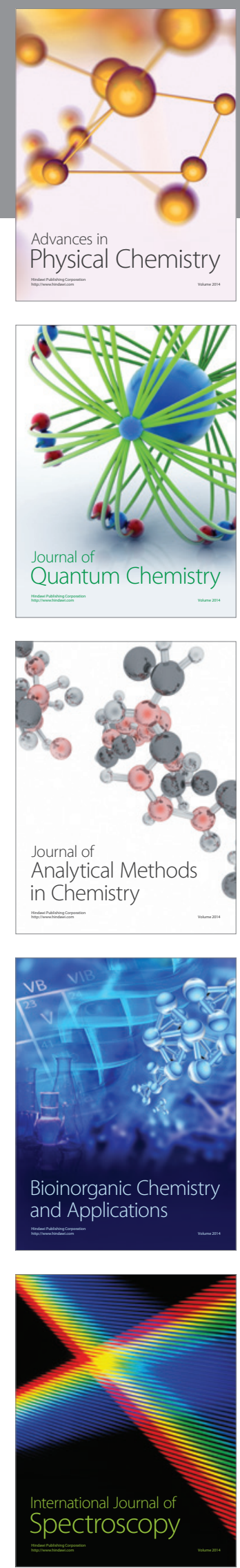